Int. J. Dev. Biol. 52: 179-185 (2008)

doi: $10.1387 / \mathrm{ijdb} .072303 \mathrm{mj}$

\title{
Accessory nuclei in insect oogenesis: in search of the function of enigmatic organelles
}

\author{
MARIUSZ K. JAGLARZ, MALGORZATA KLOC ${ }^{1}$ and SZCZEPAN M. BILINSKI* \\ Institute of Zoology, Jagiellonian University, Krakow, Poland and \\ ${ }^{1}$ Department of Biochemistry and Molecular Biology, The University of Texas M. D. Anderson Cancer Center, Houston, Texas, USA
}

\begin{abstract}
This review compiles present knowledge of the structure and molecular composition of the enigmatic cytoplasmic organelles called accessory nuclei. Most typically, they are found in the perinuclear cytoplasm in oocytes of insects and several other invertebrates. Accessory nuclei originate by budding of the oocyte nucleus (germinal vesicle) and are surrounded by an enelope identical to the nuclear envelope. They contain one or several dense inclusions called pseudonucleoli immersed in a translucent ground substance or matrix. Comparative analysis of the morphology, molecular composition and the ultimate fate of accessory nuclei and their inclusions revealed that there are two basic types of these organelles in insect oocytes. In mallophagans, accessory nuclei are associated with the oocyte nucleus throughout entire oogenesis and at least some of them are connected to the germinal vesicle by slender stems. Each accessory nucleus contains a single, dense, RNA-positive inclusion which is likely to correspond to a nucleolus. In hymenopterans, accessory nuclei initially surround the germinal vesicle but during oogenesis they separate from it and migrate toward the peripheral ooplasm. Within the accessory nucleus matrix usually two distinct inclusions develop. One of these is perfectly spherical, contains coilin and small nuclear ribonucleoproteins and is homologous to the Cajal body. In the light of recent discoveries, we discuss the role accessory nuclei play in insect oogenesis and early embryogenesis.
\end{abstract}

KEY WORDS: accessory nuclei, oogenesis, organelle distribution, snRNP, Cajal body

Oocytes are highly specialized cells whose structural and molecular components serve not only the oocyte itself but, more importantly, the future embryo. Acquisition, multiplication, and proper distribution of these components during oogenesis are of utmost importance for the course of embryogenesis. Besides the typical organelles such as mitochondria, ribosomes, and the cisterns of the Golgi apparatus and endoplasmic reticulum, whose functions and significance are well understood (reviewed in Zissler and Sander, 1982), the oocytes also contain complex cytoplasmic organelles, called accessory nuclei (AN), which have puzzled researchers since their discovery in wasp and ant oocytes by Blochmann in 1886 (Blochmann, 1886). For a long time, AN remained rather mysterious organelles of unknown function. Recent analyses using modern molecular markers identified some AN constituents and shed light on their function.

Accessory nuclei, also called nuclear membrane balloons, are characteristic organelles found primarily in perinuclear cytoplasm in oocytes of several insect species (Fig. 1A-D) and a handful of other invertebrate taxa (see Table 1). There are also rare reports of structures similar to AN in cells other than oocytes (e.g., hymenopteran nurse cells; nematode, insect, and mammalian embryonic cells), but these structures have not been investigated thoroughly, and their molecular composition and function remain largely unknown (Goldstein, 1981; Szollosi and Szollosi, 1988; Klag and Bilinski, 1994; Perondini and Ribeiro, 1997). Since the available data related to $\mathrm{AN}$ in other animals are rather fragmentary, here we focus on the origin, structure, and ultimate fate of AN present in insect oocytes.

\section{Accessory nuclei number and structure}

The newly formed AN are usually spherical or oval, but as they grow they may become pear-shaped or irregular (Figs. 1A-E, 2C, 3) (Hopkins, 1964; Buchner, 1966; King and Fordy, 1970; Cassidy

Abbreviations used in this paper: AN, accessory nuclei; OC, oocyte cytoplasm; ON, oocyte nucleus; snRNAs, small nuclear RNAs; snRNPs, small nuclear ribonucleoproteins; SMN, survival of motor neurons.

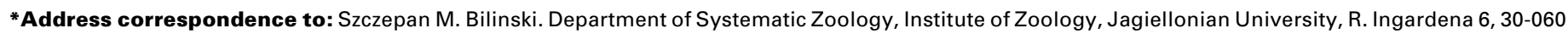
Krakow, Poland. Tel: +4812-663-2409. Fax: +4812-634-3716. e-mail: sbili@zuk.iz.uj.edu.pl
}

Published online: 14 February 2008. 
and King, 1972; Meyer et al., 1979; Zissler and Sander, 1982; Billen, 1985; Bilinski and Jankowska, 1987; Bilinski, 1989, 1991a, b; Szklarzewicz et al., 1993; Bilinski et al., 1993, 1995a, b; Jablonska and Bilinski, 2001). Depending on their developmental stage and the species, AN vary in size; they can reach 5-10 $\mu \mathrm{m}$ in diameter (Bilinski, 1991a; Ferree et al., 2006). There are usually tens or even hundreds of $\mathrm{AN}$ in a single oocyte (e.g., the late previtellogenic oocyte of the parasitic wasp Muscidifurax uniraptor contains, on average, 200 AN [Ferree et al., 2006]), and their number may increase during oocyte development as they are capable of multiplying by fission.

Like most cytoplasmic organelles, AN are separated from the surrounding cytoplasm by an outer envelope (Figs. 2C, 3, 4 arrows) that contains two membranes and is virtually identical to the nuclear envelope (King and Fordy, 1970; Meyer et al., 1979; Bilinski, 1991a; Jaglarz et al., 2005). Like its nuclear counterpart, the AN envelope is pierced by pores and covered with ribosomes, and its internal membrane, at least in some species, is lined with distinguishable lamina (Figs. 2C, 3, 4C) (Bilinski, 1989; 1991a).

TABLE 1

\section{OCCURRENCE OF ACCESSORY NUCLE IN OOCYTES OF DIFFERENT ANIMALS}

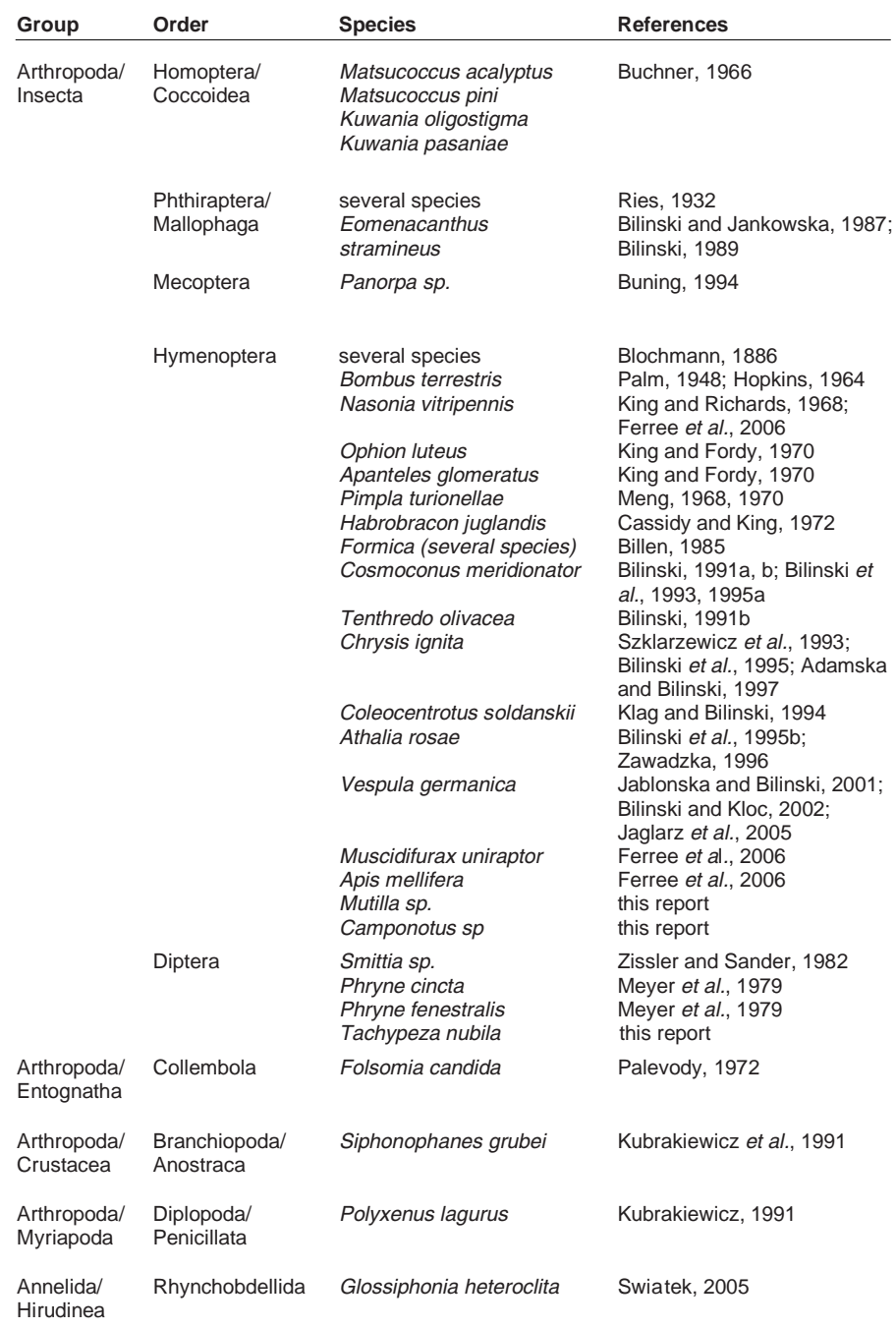

Fig. 1. Distribution of accessory nuclei (AN) in insect oocytes. (A) Tachypeza nubila (Diptera); numerous AN (white arrows) gather around a germinal vesicle (asterisk) in the center of the oocyte (O); the ooplasm is loaded with yolk spheres and lipid droplets. (B) Camponotus sp. (Hymenoptera): AN (arrows) contain dense inclusions and surround the germinal vesicle (asterisk) in the cytoplasm of the oocyte (O) anterior pole. The oocyte cytoplasm in this species is filled with bacteroids. (C) Mutila sp. (Hymenoptera), AN (arrows) are gathered around a germinal vesicle (asterisk) and occupy the anterior pole of the previtellogenic oocyte. Note dense pseudonucleoli immersed in homogenous ground substance filling the AN. (D,E) Vespula germanica (Hymenoptera). In the midprevitellogenic oocyte (O) AN (arrows) surround the germinal vesicle (asterisk) and occupy the anterior region of the oocyte cytoplasm (D). In the late previtellogenic oocyte (E) AN (arrows) are located in the anterior and lateral aspect of the cortical ooplasm. FC, follicle cells. (A-E). Epon semithin sections stained with methylene blue. Scale bars, $(A, B), 10 \mu \mathrm{m}$; $(C-E), 25 \mu \mathrm{m}$.

The latter finding has been confirmed recently by immunofluorescence staining of AN in oocytes of several hymenopteran species with an antibody against Drosophila lamin Dm0 (Ferree et al., 2006). Electron microscopy analysis of AN isolated by the spreading technique from the oocytes of the sawfly Athalia rosae demonstrated that AN nuclear pores contain ringlike structures with outer diameters measuring about $100 \mathrm{~nm}$ (Fig. 2B) (Bilinski et al., 1995). Both the shape and size of these rings correspond well with those of nuclear pore complexes, which suggests that the pores in the AN envelope function in the same way as nuclear pores do. There is no doubt that this organization of the AN envelope results from the way these organelles arise within the oocyte (see below). Electron microscopy studies have shown, furthermore, that accumulations of fine granular material often associate with both the external and internal membranes of the AN envelope (Fig. 4) (Bilinski, 1991a; Jaglarz et al., 2005).

AN are filled with electron translucent ground substance (matrix), usually containing electron-dense inclusions traditionally termed pseudonucleoli (Figs. 1B-D, 2C, 3, 4) (Hopkins, 1964; King and Fordy, 1970; Cassidy and King, 1972; Meyer etal., 1979; Bilinski, 1989, 1991a; Szklarzewicz et al., 1993). The molecular compositions of these inclusions appear to be the key to under- 


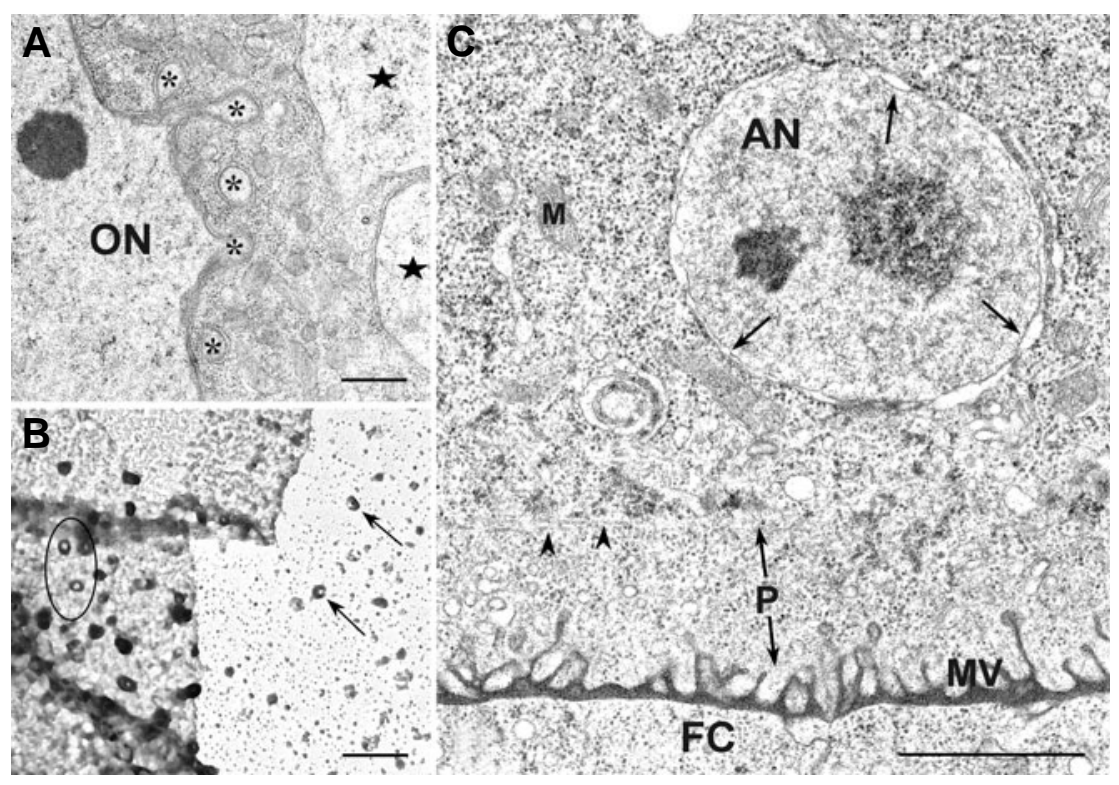

Fig. 2. Formation and morphology of hymenopteran accessory nuclei (AN). (A) Vespula germanica; an early previtellogenic oocyte. AN (asterisks) bud from the oocyte nucleus (ON) and free AN (asters) remain in the ooplasm adjacent to the oocyte nucleus. (B) Athalia rosae; a spread AN (Millerian spreading technique). Ring-like structures (nuclear pore complexes) are present on the AN surface (encircled). Similar structures outside the AN are indicated by arrows. (C) Chrysis ignita; electron micrograph of the oocyte periphery (the late previtellogenic stage). The AN, surrounded by a double-layered envelope (arrows) and containing two dense inclusions, is located in the ooplasm just beneath the organelle-free periplasm (P). The periplasm (cortical ooplasm) is separated from the remaining ooplasm by microtubules (arrowheads). FC, follicle cells; $M$, mitochondrium; MV, microvilli. Scale bars, (A) $500 \mathrm{~nm}$, (B) $400 \mathrm{~nm}$, (C) $1 \mu \mathrm{m}$.

standing AN function(s), and they are discussed at greater length in the next section.

\section{AN morphogenesis and the nature of pseudonucleoli}

The morphogenesis of AN has been documented only in a small number of species, such as the bird louse Eomenacanthus stramineus (Bilinski, 1989) and certain hymenopteran species (Hopkins, 1964; King and Fordy, 1970; Cassidy and King, 1972; Bilinski, 1991a; Klag and Bilinski, 1994). Regardless of the species, the AN originate from the germinal vesicle by budding or folding of its envelope (Fig. 2A, asterisks). In this process, at least in the bird louse, a thick nuclear lamina is involved (Fig. 3) (Bilinski, 1989). Bilinski (1991a) suggested that, in hymenopteran oocytes, microtubules surrounding the germinal vesicles play a role in AN budding and/or stabilization.

Comparative analysis of AN during different stages of oogenesis in various insect groups indicates that there are two basic types of AN distribution within the ooplasm (schematically presented in Fig. 5). In the mallophagan E. stramineus, first AN buds appear during early previtellogenesis (Fig. 3) (Bilinski and Jankowska, 1987). The newly formed AN contain accumulations of fibrillogranular material, which are RNA-negative but stain with silver in the Ag-NOR method (Bilinski, 1989). Subsequently, AN enlarge and often become elongated or pear-shaped. The growing AN gather around the oocyte nucleus and maintain this perinuclear position throughout vitellogenesis (Fig. 5B). Con- comitantly, inside each AN, a single, dense, RNApositive inclusion develops (Fig. 3, inset) (Bilinski, 1989). Bilinski (1989) postulated that in $E$. stramineus, AN contain transcriptionally active extrachromosomal rDNA that was extruded from the germinal vesicles. If this is true, then the pseudonucleoli will be an equivalent of the multiple nucleoli present in oocyte nuclei of other insect species (for review see Buning, 1994).

In hymenopterans, AN also form by germinal vesicle budding (Fig. $2 \mathrm{~A}$ ), but their ultimate fate is different (Fig. 5A). In all hymenopteran species studied to date, AN form during previtellogenic growth of the oocyte (Hopkins, 1964; Meng, 1968; King and Fordy, 1970; Bilinski, 1991a). Initially they surround the germinal vesicle (Figs. 1B-D, 2A, $5 \mathrm{~A})$, but as oogenesis progresses and the oocyte elongates along its anterior-posterior axis (late previtellogenesis), a majority of the AN separate from the germinal vesicle and translocate toward the peripheral ooplasm, where they grow and often multiply (Figs. 1E arrows, 2C, 5A) (Hopkins, 1964; Meng, 1968; King and Fordy, 1970; Bilinski, 1991a). They maintain this distribution throughout vitellogenesis. Only a small number of AN remain in the perinuclear cytoplasm and accompany the germinal vesicle as it migrates laterally (i.e., to the future dorsal side of the embryo [Fig. 5A]).

The ooplasm (oocyte cytoplasm) in hymenopterans is clearly separated into thin, translucent organelle-free periplasm and the opaque organellerich endoplasm (Fig. 2C) (Bilinski, 1991b). Ultrastructural analysis showed that, upon arrival at the oocyte periphery, AN associate with a subcortical microtubule network that separates these two types of ooplasm (Fig. 2C) (Bilinski et al., 1995a). Treatment of oocytes with the microtubule-assembly inhibitor colchicine indicates that microtubule cytoskeleton is responsible for maintaining the peripheral (subcortical) distribu-

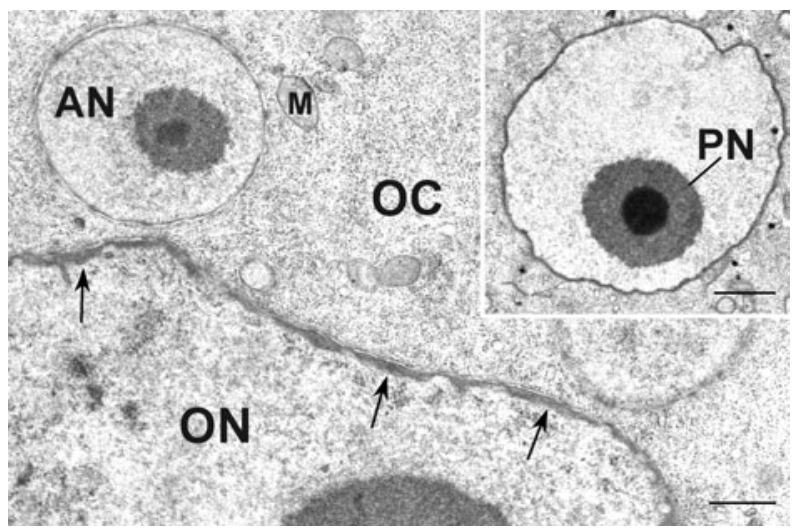

Fig. 3. Morphology of an accessory nucleus in Eomenacanthus stramineus; electron micrograph of the perinuclear region. Note a newly formed accessory nucleus (AN) in the oocyte cytoplasm (OC) adjacent to the oocyte nucleus (ON). $M$, mitochondrium; arrows indicate a well-developed nuclear lamina. (Inset) A mature accessory nucleus with a prominent pseudonucleolus (PN) immersed in the electron translucent ground substance. Scale bar, $500 \mathrm{~nm}$. 

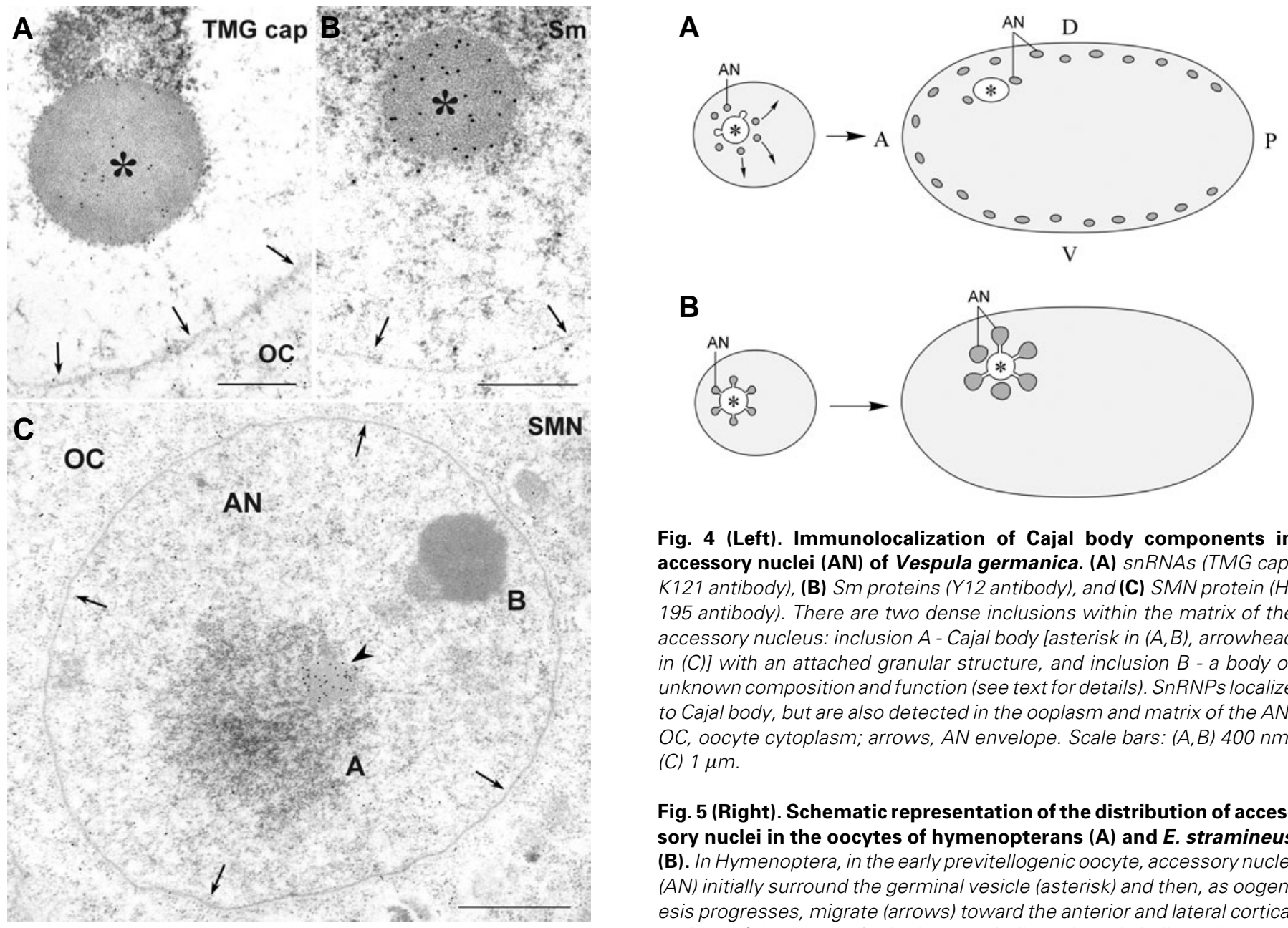

Fig. 4 (Left). Immunolocalization of Cajal body components in accessory nuclei (AN) of Vespula germanica. (A) snRNAs (TMG cap; K121 antibody), (B) Sm proteins (Y12 antibody), and (C) SMN protein (H195 antibody). There are two dense inclusions within the matrix of the accessory nucleus: inclusion $A$ - Cajal body lasterisk in $(A, B)$, arrowhead in (C)] with an attached granular structure, and inclusion $B-a$ body of unknown composition and function (see text for details). SnRNPs localize to Cajal body, but are also detected in the ooplasm and matrix of the AN. OC, oocyte cytoplasm; arrows, AN envelope. Scale bars: $(A, B) 400 \mathrm{~nm}$, (C) $1 \mu \mathrm{m}$.

Fig. 5 (Right). Schematic representation of the distribution of accessory nuclei in the oocytes of hymenopterans (A) and $E$. stramineus (B). In Hymenoptera, in the early previtellogenic oocyte, accessory nuclei (AN) initially surround the germinal vesicle (asterisk) and then, as oogenesis progresses, migrate (arrows) toward the anterior and lateral cortical regions of the oocyte. In the late previtellogenic and vitellogenic oocyte AN occupy the cortical layer, with the exception of the oocyte posterior pole. A - anterior, D - dorsal, P - posterior, V - ventral. In E. stramineus (and possibly other mallophagans), in the early previtellogenic oocyte, accessory nuclei (AN) are gathered around the germinal vesicle (asterisk). During oogenesis they migrate together with the germinal vesicle to a certain region of the oocyte and remain there till the completion of oogenesis. Throughout oogenesis at least some accessory nuclei remain connected to the germinal vesicle by slender stems (diagrams not to scale).

tion of the AN (Bilinski et al., 1995a; Adamska and Bilinski, 1997).

Hymenopteran AN contain one or several electron-dense pseudonucleoli immersed in more or less transparent matrix (Figs. 1B-D, 2C, 4A-C) (Hopkins, 1964; King and Fordy, 1970; Cassidy and King, 1972; Bilinski, 1989; 1991a, b; Szklarzewicz et al., 1993; Jablonska and Bilinski, 2001; Bilinski and Kloc, 2002; Jaglarz et al., 2005; Ferree et al., 2006). Pseudonucleoli have been studied in detail in queens of the German wasp, Vespula germanica. In this species, AN in previtellogenic oocytes usually contain two morphologically different pseudonucleoli (Fig. 4C). One (here termed inclusion $A$ ) is composed of a perfectly spherical homogenous body with an attached hemispherical structure comprising numerous electron-dense 20 - to $30-\mathrm{nm}$ particles (Figs. 4A, B asterisks, 4C arrowhead) (Jablonska and Bilinski, 2001; Bilinski and Kloc, 2002; Jaglarz et al., 2005). The other pseudonucleolus (termed inclusion $B$ ) is less regular in shape and consists of fine flocculent or amorphous material (Fig. 4C).

Interestingly, AN are also present in oocytes of wasp workers, but they are less numerous and contain more inclusions of both types. These inclusions are not only larger than those in queen oocytes, but also have more complex ultrastructure (Jablonska and Bilinski, 2001, Bilinski and Kloc, 2002). Since oogenesis in $V$. germanica workers terminates prematurely at the midprevitellogenic stage, it is possible that this may have a deleterious effect on the processes involved in the formation of inclusions, even though AN bud correctly.

Cytochemical studies of AN of queen oocytes have shown that they are devoid of DNA but their inclusions contain nucleolar organizer proteins (Ag-NOR proteins) (Bilinski and Kloc, 2002). Immunocytochemical analysis showed that the spherical body of inclusion A contains molecules characteristic of the Cajal body: its signature protein coilin, small nuclear RNAs (snRNAs), small nuclear ribonucleoproteins (snRNPs), and survival of motor neurons (SMN) protein (Fig. 4A-C) (Bilinski and Kloc, 2002; Jaglarz et al., 2005). These findings indicate that the spherical body of inclusion A is homologous to the Cajal body (for the latest reviews on Cajal body structure and functions see Gall, 2000, 2003; Cioce and Lamond, 2005; Matera, 2006; Stanek and Neugebauer, 2006). Interestingly, immunolocalization studies have shown that snRNPs, in addition to being present in the spherical body of 
inclusion $A$, are also present in small foci on both sides of the AN envelope (Fig, 4B, C) (Jaglarz et al., 2005). These results led to the suggestion that in hymenopteran oocytes, snRNAs, after their association with appropriate proteins and hypermethylation (for description of snRNP biogenesis see Box 1), are transferred from the cytoplasm via nuclear pores into the AN matrix, where they gradually assemble into a larger inclusion, the Cajal body (Jaglarz et al., 2005). Alternatively, snRNAs (hypermethylated and associated with Sm proteins and the SMN complex) might return to the nucleoplasm (as happens in all other eukaryotic cells) and might be loaded to the young AN as they bud from the germinal vesicle. Both these models are schematically shown in Fig. 6. Interestingly, inclusions B are not related to the biogenesis of snRNPs (they were negative in all immunocytochemical tests already mentioned) and thus must be engaged in some other cellular processes. It has been recently reported that in the honeybee, Apis mellifera, each AN contains distinct $\gamma$-tubulin foci, and that in early embryos of the parasitic wasps Nasonia vitripennis and $M$. uniraptor the microtubule-organizing centers (centrosomes) originate from AN (Ferree et al., 2006). These results led to the suggestion that $\mathrm{AN}$ facilitate centrosome formation by sequestering and concentrating $\gamma$-tubulin in the periplasm. Since immunoelectron microscopy studies have not been performed, the precise localization of $\gamma$-tubulin within AN is currently unknown.

Although the results just described may appear somewhat

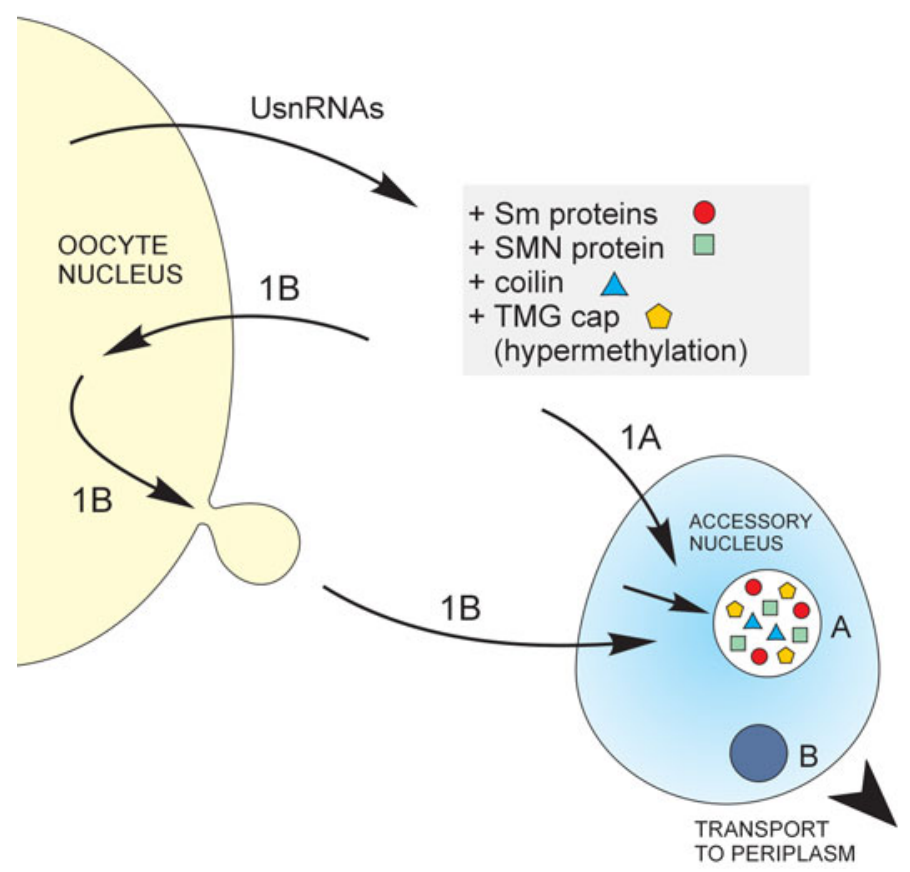

Fig. 6. Schematic representation of the snRNP translocation in hymenopteran oocytes. During previtellogenesis, $U$ snRNAs are exported from the oocyte nucleus into the cytoplasm and after association with SMN and Sm proteins form the $U$ snRNP particles, which are hypermethylated at the $5^{\prime}$ end. Subsequently, snRNPs might be transported directly into accessory nuclei and their Cajal bodies (inclusion A; pathway $1 \mathrm{~A}$ ) or alternatively, they are transported back into the oocyte nucleus and after the formation of accessory nuclei into their Cajal bodies (pathway 1B). Ultimately, accessory nuclei with their Cajal bodies and inclusions $B$ are transported towards the oocyte periplasm.

\section{Box 1}

\section{Biogenesis of small nuclear ribonucleoproteins}

Small nuclear ribonucleoproteins (snRNPs) are essential components of RNA processing events (reviewed in Will and Luhrmann, 2001; Paushkin et al., 2002; Meister et al., 2002; Kiss, 2002, 2004; Gubitz et al., 2004). They are involved in pre-mRNA splicing (U1, U2, U5 and U4/U6 snRNPs), and histone pre-mRNA 3'-end processing (U7 snRNP). Each snRNP particle consists of a centrally located snRNA molecule, which is associated with a set of specific proteins.

The biogenesis of spliceosomal snRNPs starts in the nucleus, with transcription of the snRNAs. Subsequently, the snRNAs (except U6 snRNAs) are exported from the nucleus, through nuclear pores, into the cytoplasm, where they associate with several proteins (e.g., Sm proteins, survival of motor neurons [SMN] protein) and form snRNPs (Massenet et al., 2002; Meister et al., 2002; Pellizzoni et al., 2002). The SMN protein functions as part of a multiprotein complex, called SMN complex, which is necessary for assembling Sm proteins (Sm core) on the snRNAs (reviewed in Gubitz et al., 2004). Moreover, within the cytoplasm the cap structure at the $5^{\prime}$ end of snRNAs undergoes hypermethylation and forms the 2,2,7-trimethylguanosine (TMG) cap. The properly assembled Sm core and the TMG cap are prerequisites for transport of the snRNP particle back into the nucleus, where it is targeted to the Cajal body for further processing (for latest reviews see Will and Luhrmann, 2001; Paushkin et al., 2002; Gubitz et al., 2004; Yong et al., 2004).

Biogenesis of spliceosomal snRNPs follows a similar pathway in all eukaryotic organisms studied thus far (reviewed in Paushkin et al., 2002; Gubitz et al., 2004; Yong et al., 2004).

contradictory, in fact, they complement each other quite well if one assumes that $\gamma$-tubulin-positive foci in AN of $A$. mellifera are an equivalent of inclusions $B$ of other hymenopterans. It is tempting to speculate that hymenopteran AN contain factors responsible for biogenesis of snRNPs (in inclusions A) and $\gamma$-tubulin (in inclusions $\mathrm{B}$ ), and are involved in the translocation of these molecules to the cortical region of the oocyte (see below).

\section{AN ultimate fate and role in hymenopterans}

The final fate of $\mathrm{AN}$ and their inclusions have been elucidated only in hymenopteran oocytes. Bilinski et al. (1993) and Jaglarz et al. (2005) showed that, in hymenopterans, soon after AN arrive at the oocyte cortex, their inclusions (both A and B) break down and disperse in the AN matrix. Immunolocalization and in situ hybridization showed that the components of Cajal bodies are retained within AN until late oogenesis (Jaglarz et al., 2005). Finally, at the end of vitellogenesis or during the transition to embryogenesis, AN disintegrate, releasing their cargo into surrounding cortical ooplasm (Jaglarz et al., 2005; Ferree et al., 2006). Similar fates of $A N$ and their inclusions have been observed in other hymenopteran species, indicating evolutionary conservatism of these processes in this insect order (Bilinski et al., 1993; Szklarzewicz et al., 1993; Jaglarz et al., 2005; Ferree et al., 2006). This behaviour of hymenopteran AN suggests that they function as vehicles for the transport and localization of snRNPs (Bilinski and Kloc, 2002; Jaglarz etal., 2005) and $\gamma$-tubulin (Ferree 
et al., 2006) to the oocyte cortical region and serve as temporary storage sites for these factors. Therefore hymenopteran oocytes utilize AN for distributing snRNPs, centrosomal proteins, and possibly some other factors of maternal origin to the cortical region, where they are needed during initial stages of embryonic development. In most insects, early embryonic stages of development are confined to the cortical region of the egg (the superficial cleavage) and it is here where the blastoderm forms (1), massive transcriptional activity of blastoderm nuclei starts (2), and blastoderm cells intensively multiply by mitotic divisions (3) (reviewed in Zissler, 1992; Buning, 1994). Thus the accumulation of snRNPs and $\gamma$-tubulin in the cortical region of the oocyte might be directly linked to the intensity of these processes.

Thanks to recent discoveries, a more general picture of the role of $\mathrm{AN}$ in insect oocytes is beginning to emerge. Despite similar origins, $A N$ in mallophagans and those in hymenopterans have different distributions and are involved in different cellular processes during oogenesis and/or early embryonic development. This supports the hypothesis that AN evolved independently in several not closely related insect groups/lineages (Meyer et al., 1979). In this context, a comparative analysis of AN molecular composition and function in other insects and other animal groups may provide further insight into the complexity of oocyte compartmentalization and its significance for early embryonic development.

\section{Acknowledgements}

We would like to thank Miss E. Kisiel for the drawings.

\section{References}

ADAMSKA, M. and BILINSKI, S.M. (1997) Microtubules are responisble for the asymmetrical distribution of organelles in the oocytes of the hymenopteran, Chrysis ignita. Folia Histochem. Cytobiol. 35: 221-225.

BILINSKI, S.M. (1989) Formation and function of accessory nuclei in the oocytes of the bird louse, Eomenacanthus stramineus (Insecta: Mallophaga). I. Ultrastructural and histochemical studies, Chromosoma 97: 321-326.

BILINSKI, S.M. (1991a) Are accessory nuclei involved in the establishment of developmental gradients in hymenopteran oocytes? Ultrastructural studies. Roux's Arch. Dev. Biol. 199: 423-426.

BILINSKI, S.M. (1991b) Morphological markers of anterioposterior and dorsoventral polarity in developing oocytes of the hymenopteran Cosmoconus meridionator (Ichneumonidae). Roux's Arch. Dev. Biol. 200: 330-335.

BILINSKI, S.M. and JANKOWSKA, W. (1987) Oogenesis in the bird louse Eomenacanthus stramineus (Insecta: Mallophaga). I. General description and structure of the egg capsule. Zool. Jb. Anat. 116: 1-12.

BILINSKI, S.M., KLAG, J. and KUBRAKIEWICZ, J. (1993) Morphogenesis of accessory nuclei during final stages of oogenesis in Cosmoconus meridionator (Hymenoptera: Ichneumonidae). Roux's Arch. Dev. Biol. 203: 100-103.

BILINSKI, S.M., KLAG, J. and KUBRAKIEWICZ, J. (1995a) Subcortical microtubule network separates the periplasm from the endoplasm and is responsible for maintaining the position of accessory nuclei in hymenopteran oocytes. Roux's Arch. Dev. Biol. 205: 54-61.

BILINSKI, S.M. and KLOC, M. (2002) Accessory nuclei revisited: the translocation of snRNPs from the germinal vesicle to the periphery of the future embryo. Chromosoma 111: 62-68.

BILINSKI, S.M., ZAWADZKA, M. and BUNING, J. (1995b) Visualization of accessory nuclei from oocytes of the sawfly, Athalia rosae (Hymenoptera: Tenthredinidae) by a spreading technique. Folia Histochem. Cytobiol. 33: 197200.

BILLEN, J. (1985) Ultrastructure of the worker ovarioles in Formica ants ( Hymenoptera: Formicidae). Int. J. Insect Morphol. Embryol. 14: 21-32.
BLOCHMANN, F. (1886) Uber die Reifung der Eier bei Ameisen und Wespen. Festschrift Naturh. Med. Verein Heilderberg.

BUCHNER, P. (1966) Endosymbiosestudien an Schildläusen. VIII. Die Symbiosen der Palaeococcoidea. Z. Morph. Okol. Tiere 56: 275-362.

BUNING, J. (1994) The insect ovary. Ultrastructure, previtellogenic growth and evolution. Chapman and Hall, London.

CASSIDY, J.D. and KING, R.C. (1972) Ovarian development in Habrobracon juglandis (Ashmead) (Hymenoptera: Braconidae). I. The origin and differentiation of the oocyte - nurse cell complex. Biol. Bull. 143: 483-505.

CIOCE, M. and LAMOND, A.I. (2005) Cajal bodies: a long history of discovery. Annu. Rev. Cell Dev. Biol. 21: 105-131.

FERREE, P.M., MCDONALD, K., FASULO, B. and SULLIVAN, W. (2006) The origin of centrosomes in parthenogenetic hymenopteran insects. Curr. Biol. 16: 801807.

GALL, J.G. (2000) Cajal bodies: the first 100 years. Annu. Rev. Cell Dev. Biol. 16: 273-300.

GALL, J.G. (2003) The centennial of the Cajal body. Nat. Rev. Mol. Cel/ Biol. 4: 975 980.

GOLDSTEIN, P. (1981) Accessory nuclei in female Ascaris suum. J. Parasitol. 67: 697-701.

GUBITZ, A.K., FENG, W. and DREYFUSS, G. (2004) The SMN complex. Exp. Cell Res. 296: 51-56.

HOPKINS, C.R. (1964) The histochemistry and fine structure of the accessory nuclei in the oocyte of Bombus terrestris. Quart. J. Microsc. Sci. 105: 475-480.

JABLONSKA, A. and BILINSKI, S.M. (2001) Structure of ovarioles in adult queens and workers of the common wasp, Vespula germanica(Hymenoptera: Vespidae) Folia Biol. (Krakow) 49: 191-198.

JAGLARZ, M.K., BILINSKI, S.M. and KLOC, M. (2005) Assembly and breakdown of Cajal bodies in accessory nuclei of Hymenoptera. Differentiation 73: 99-108.

KING, P.E. and FORDY, M.R. (1970) The formation of "accessory nuclei" in the developing oocytes of parasitoid hymenopterans Ophion luteus (L.) and Apanteles glomeratus (L.). Z. Zellforsch. 109: 158-170.

KING, P.E. and RICHARDS, J.G. (1968) Accessory nuclei and annulate lamellae in hymenopteran oocytes. Nature 218: 488.

KISS, T. (2002) Small nucleolar RNAs: an abundant group of noncoding RNAs with diverse cellular functions. Cel/109: 145-148.

KISS, T. (2004) Biogenesis of small nuclear RNPs. J. Cell Sci. 117: 5949-5951.

KLAG, J. and BILINSKI, S M. (1994) Germ cell cluster formation and oogenesis in the hymenopteran Coleocentrotus soldanskii. Tissue Cel/26: 699-706.

KUBRAKIEWICZ, J. (1991) Ovary structure and oogenesis of Polyxenus lagurus (L.) (Diplopoda, Pselaphognatha). An ultrastructural study. Zool. Jb. Anat. 121: $81-93$.

KUBRAKIEWICZ, J., ADAMSKI, R.T. and BILINSKI, S.M. (1991) Ultrastructural studies on accessory nuclei in developing oocytes of the crustacean, Siphonophanes grubei. Tissue Cel/23: 903-907.

MASSENET, S., PELLIZZONI, L., PAUSHKIN, S., MATTAJ, I.W. and DREYFUSS G. (2002) The SMN complex is associated with snRNPs throughout their cytoplasmic assembly pathway. Mol. Cell. Biol. 22: 6533-6541.

MATERA, A.G. (2006) Drosophila Cajal bodies: accessories not included. J. Cell Biol. 172: 791-793.

MEISTER, G., EGGERT, C. and FISCHER, U. (2002) SMN-mediated assembly of RNPs: a complex story. Trends Cell Biol. 12: 472-478.

MENG, C. (1968) Strukturwandel und histochemische Befunde insbesondere am Oosom während der Oogenese und nach der Ablage des Eies von Pimpla turionellae L. (Hymenoptera, Ichneumonidae). W. Roux's Arch. 161: 162-208.

MENG, C. (1970) Autoradiographische Untersuchungen am Oosom in der Oocyte von Pimpla turionellae L. (Hymenoptera, Ichneumonidae). W. Roux's Arch. 165: $35-52$.

MEYER, G.F., SOKOLOFF, S., WOLF, B.E. and BRAND, B. (1979) Accessory nuclei (nuclear membrane balloons) in the oocytes of dipteran Phryne. Chromosoma 75: 89-99.

PALEVODY, C. (1972) Presence de noyaux accessoires dans l'ovocyte du Collembole Folsomia candida Willem (Insecte, Apterygote). C. R. Acad. Sci. Paris 274: 3258-3261. 
PALM, N.-B. (1948) Normal and pathological histology of the ovaries in Bombus Latr. (Hymenopt.) Opus. Entomol. Suppl. VII, 1-101.

PAUSHKIN, S., GUBITZ, A.K., MASSENET, S. and DREYFUSS G. (2002) The SMN complex, an assemblyosome of ribonucleoproteins. Curr. Opin. Cell Biol. 14: 305-312.

PELLIZZONI, L., YONG, J. and DREYFUSS, G. (2002) Essential role for the SMN complex in the specificity of snRNP assembly. Science 298: 1775-1779.

PERONDINI, A.L.P. and RIBEIRO, A.F. (1997) Chromosome elimination in germ cells of Sciara embryos: involvement of the nuclear envelope. Invert. Rep. Dev. 32: 131-141.

RIES, E. (1932) Die Prozesse der Eibildung und das Eiwachstum bei Pediculiden und Mallophagen. Z. Zellforsch. Mikrosk. Anat. 16: 314-388.

STANEK, D. and NEUGEBAUER, K.M. (2006) The Cajal body: a meeting place for spliceosomal snRNPs in the nuclear maze. Chromosoma 115: 343-354.

SWIATEK, P. (2005) Structure of the germinal vesicle during oogenesis in leech Glossiphonia heteroclita (Annelida, Hirudinea, Rhynchobdellida). J. Morphol. 263: 330-339.
SZKLARZEWICZ, T., BILINSKI, S.M., KLAG, J. and JABLONSKA, A. (1993) Accessory nuclei in the oocytes of the cockoo wasp, Chrysis ignita (Hymenoptera: Aculeata). Folia Histochem. Cytobiol. 31: 227-231.

SZOLLOSI, M.S. and SZOLLOSI, D. (1988) "Blebbing" of the nuclear envelope of mouse zygotes, early embryos and hybrid cells. J. Cell Sci. 91: 257-267.

WILL, C.L., and LUHRMANN, R. (2001) Spliceosomal UsnRNP biogenesis, structure and function. Curr. Opin. Cell Biol. 13: 290-301.

YONG, J., WAN, L. and DREYFUSS, G. (2004) Why do cells need an assembly machine for RNA-protein complexes? Trends Cell Biol. 15: 226-232.

ZAWADZKA, M. (1996) Distribution of accessory nuclei in the oocytes of the sawfly, Athalia rosae (Hymenoptera: Tenthredinidae). Folia Biol. (Krakow) 44: 61-66.

ZISSLER, D. (1992) From egg to pole cells: ultrastructural aspects of early cleavage and germ determination in insects. Microsc. Res. Tech. 22: 49-74.

ZISSLER, D. and SANDER, K. (1982) The cytoplasmic architecture of the insect egg cell. [in:] Insect Ultrastructure. R.C. King and H. Akai [Eds.] vol.1, pp 189221. New York: Plenum Press.

\section{Related, previously published Int. J. Dev. Biol. articles}

See our recent Special Issue Developmental Biology in Poland edited by Kloc, Maleszewski and Tarkowski at: http://www.ijdb.ehu.es/web/contents.php?vol=52\&issue=2-3

See our Special Issue Mammalian Reproduction \& Development in honor of Anne McLaren and edited by Brigid Hogan at: http://www.ijdb.ehu.es/web/contents.php?vol=45\&issue=3

Accumulation and dynamics of proteins of the MCM family during mouse oogenesis and the first embryonic cell cycle

Lukasz Swiech, Katarzyna Kisiel, Renata Czolowska, Maciej Zientarski and Ewa Borsuk

Int. J. Dev. Biol. (2007) 51: 283-295

Stage-specific regulation of programmed cell death during oogenesis of the medfly Ceratitis capitata (Diptera, Tephritidae) Athanassios D. Velentzas, loannis P. Nezis, Dimitrios J. Stravopodis, Issidora S. Papassideri and Lukas H. Margaritis Int. J. Dev. Biol. (2007) 51: 57-66

Delivery of germinal granules and localized RNAs via the messenger transport organizer pathway to the vegetal cortex of Xenopus oocytes occurs through directional expansion of the mitochondrial cloud

Katarzyna Wilk, Szczepan Bilinski, Matthew T. Dougherty and Malgorzata Kloc

Int. J. Dev. Biol. (2005) 49: 17-21

Identification of an amphibian oocyte nuclear protein as a candidate for a role in embryonic DNA replication.

S Bucci, M Ragghianti, I Nardi, M Bellini, G Mancino and J C Lacroix Int. J. Dev. Biol. (1993) 37: 509-517

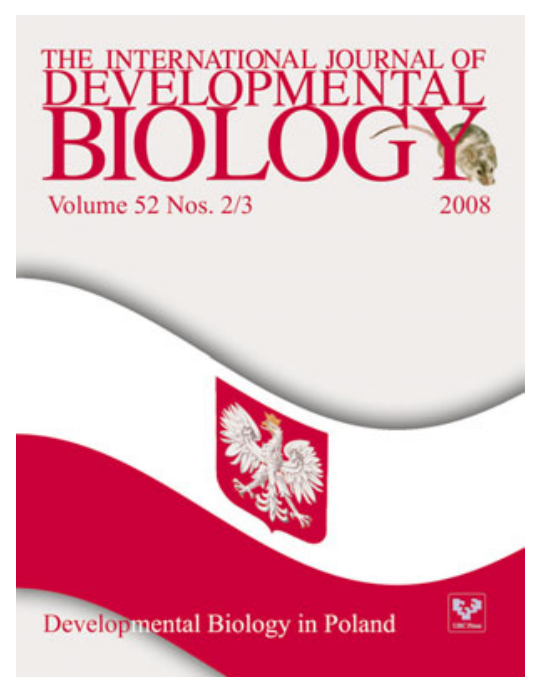

2006 ISI ${ }^{\star *}$ Impact Factor $=3.577^{\star *}$

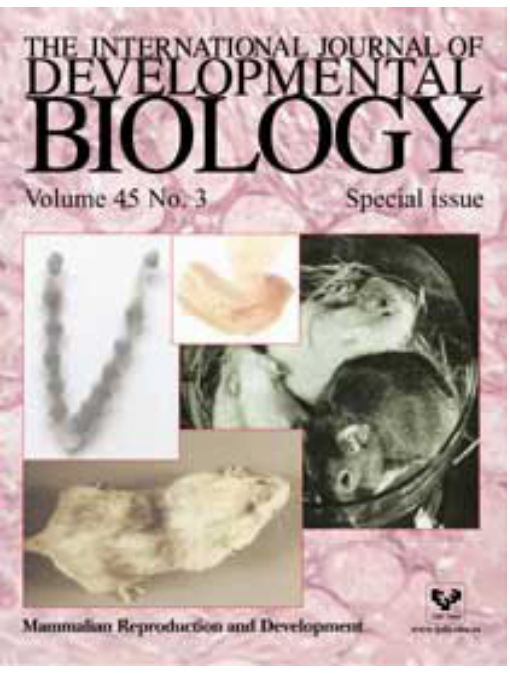

